\title{
Formação Continuada de Professores que Lecionam Matemática: desenvolvendo a prática reflexiva docente
}

\author{
Continuing Education for Math Teachers: Developing Reflective Teaching \\ Practices
}

\author{
Angélica da Fontoura Garcia Silva* \\ Maria de Lurdes Serrazina** \\ Tânia Maria Mendonça Campos ${ }^{* * *}$
}

\begin{abstract}
Resumo
Este artigo apresenta as discussões e parte dos resultados de uma pesquisa desenvolvida durante três anos em uma escola de Ensino Fundamental. No estudo apresentado foram analisadas reflexões sobre a prática docente, realizadas por um grupo de 17 professores de Matemática que lecionavam para os Anos Iniciais em um contexto de um curso de formação continuada. A coleta de dados incluiu os depoimentos colhidos durante o processo de formação e entrevistas semiestruturadas realizadas depois da intervenção do professor. Teoricamente, esta investigação fundamentou-se tanto em teorias que discutem questões relacionadas à formação de professores como em estudos que investigam questões didáticas sobre a fração. A análise dos dados permitiu identificar que a reflexão observada durante o processo de formação propiciou, além do avanço na compreensão do objeto matemático, o aprimoramento da análise de questões didáticas do conteúdo.
\end{abstract}

Palavras-chave: Educação Matemática. Educação Continuada de Professores. Professores dos Anos Iniciais. Mudanças nas Práticas de Professores.

\begin{abstract}
This article presents the discussions and part of the results from a research carried out over a three-year-period in an elementary school setting. In the study, we analyzed reflections on teaching practices from 17 math teachers from an elementary school who took part in a continuing education course. Data collection included interviews obtained during the training process and semi-structured interviews conducted after the intervention of the teacher. This research was based both on theoretical discussions related to teacher training as well as studies investigating didactic questions on teaching fractions. Data analysis identified that reflections observed during training provided, in addition to advancing the understanding of mathematical object, improved analysis of didactic content.
\end{abstract}

\footnotetext{
* Doutora em Educação Matemática pela Pontifícia Universidade Católica de São Paulo (PUC), São Paulo, São Paulo, Brasil. Professora do Programa de Pós-Graduação em Educação Matemática da Universidade Anhanguera de São Paulo (UNIAN), São Paulo, São Paulo, Brasil. Endereço para correspondência: Rua Antônio Celeguim, 180, CEP: 07850-060, Franco da Rocha- SP, Brasil.E-mail: angelicafontoura@gmail.com

** PhD pela University of London, Londres, Inglaterra. Professora Coordenadora Aposentada da Escola Superior de Educação do Instituto Politécnico de Lisboa, Lisboa, Portugal. Membro integrado da Unidade de Investigação e Desenvolvimento em Educação e Formação (UIDEF); Universidade de Lisboa. Endereço para correspondência: Campus de Benfica do IPL, 1549-003, Lisboa, Portugal. E-mail: lurdess@eselx.ipl.pt

**** Pós-doc em Matemática pela Universidade de Londres, em 1991, Londres, Inglaterra, e em Educação Matemática na University de Oxford, em 2007, Oxford, Inglaterra. Coordenadora do Programa de PósGraduação em Educação Matemática da Universidade Anhanguera de São Paulo, São Paulo, São Paulo, Brasil. Endereço para correspondência: Rua Dr. Fausto Ferraz, 61, ap 151, CEP: 01333-030, São Paulo - SP, Brasil. Email: taniammcampos@hotmail.com
} 
Keywords: Mathematics Education; Continuing Education for Teachers; Elementary School Teachers; Changes in Teacher Practices

\section{Introdução}

No sentido de organizar o trabalho pedagógico e proporcionar aos alunos oportunidades que favoreçam, efetivamente, a compreensão da Matemática como ciência harmônica, fruto da criação do homem, consideramos a importância do papel do professor. Muitas são as expectativas sobre o perfil desse profissional em face da tarefa de realizar um ensino de qualidade, e, certamente, uma formação inicial adequada poderia ser um bom começo, mas não o suficiente. Nesse sentido, ações estratégicas de formação continuada se fazem necessárias. Desse modo, nosso estudo (GARCIA SILVA, 2007) foi realizado com o objetivo de analisar diferentes fatores que podem interferir no desenvolvimento profissional de professores dos primeiros anos do Ensino Fundamental, quando estes estão inseridos em um processo de formação em serviço. Para este artigo escolhemos apresentar parte desse estudo no qual investigaremos diferentes aspectos relacionados à reflexão de um grupo de professores, tomando como base suas observações sobre o processo de ensino e aprendizagem de frações verificada na prática desses profissionais.

Para delimitar nosso problema de pesquisa, notadamente de cunho qualitativointerpretativo apresentamos a fundamentação teórica, a metodologia de pesquisa e uma síntese da análise dos dados, obtidas por intermédio dos depoimentos de professores, os quais indicaram reflexões sobre a própria prática.

\section{Reflexão e Conhecimento do Professor}

Os termos professor reflexivo, ensino reflexivo, professor prático reflexivo tornaramse palavras-chave em muitas reformas mundiais e, em especial, no Brasil. Nesse contexto, consideramos a reflexão não como um adjetivo, mas como um conceito ${ }^{1}$. Como adjetivo, seria um atributo do professor, o que levaria ao encerramento da discussão em torno das características e dos princípios relacionados ao ensino reflexivo, desconsiderando sua importância como movimento teórico de compreensão do trabalho docente. Tais questões, hoje amplamente discutidas pela comunidade acadêmica, foram introduzidas entre nós desde os estudos de Schön (1983), reflexão esta que também esteve associada ao "poder

\footnotetext{
${ }^{1}$ Reflexão como adjetivo pressupõe que, se a reflexão é inerente ao ser humano e o professor é um ser humano, então o professor é um ser reflexivo.
} 
emancipatório" dos professores (ZEICHNER, 1993; SERRAZINA, 1999; entre outros).

Schön influenciou a difusão do conceito de reflexão. Seus estudos ${ }^{2}$ no campo da formação profissional contribuíram para popularizar e estender ao campo da formação de professores e às teorias sobre a epistemologia da prática, em oposição ao que designa de racionalismo técnico.

Schön, em 1983, no livro The reflective practitioner, já propunha a questão do conhecimento profissional, cujo eixo orientador estava relacionado à competência e o talento que os profissionais práticos (da arquitetura, música e psicanálise) têm para agir no indeterminado, porque desenvolvem uma forma de pensar no que fazem enquanto fazem. Nesse contexto, surgem noções fundamentais, e Schön defende que o saber profissional se traduz em um conjunto de competências marcadas pela prática da reflexão em diferentes níveis:

- Conhecimento na ação (knowing-in-action) - é o conhecimento que os profissionais demonstram na execução da ação;

- Reflexão na ação (reflection-in-action) - são descrições verbais ocorridas enquanto os profissionais atuam;

- Reflexão sobre a ação (reflection-on-action) - é a reconstrução mental da ação para tentar analisá-la retrospectivamente.

Observamos que o documento oficial Referenciais para Formação de Professores (BRASIL, 2002) também exprime o saber profissional docente nesse conjunto de competências:

\begin{abstract}
Assim, pode-se dizer que existe sempre um conhecimento prático que se mostra nas ações cotidianas do professor e uma reflexão durante a ação, pois constantemente ele precisa tomar atitudes imediatas; mas esse conhecimento precisa ser potencializado no processo de formação por meio da reflexão a posteriori, de forma que, compreendendo o conhecimento subjacente à sua atuação, o professor possa ampliálo, transformá-lo e torná-lo alimento para novas ações (BRASIL, 2002, p. 31).
\end{abstract}

Assim como nas pesquisas, as ideias de Schön foram amplamente divulgadas e utilizadas como fundamentação para reformas curriculares em diferentes países. Não obstante, suas ideias sofreram algumas críticas em virtude de terem sido consideradas reducionistas, ou seja, os profissionais eram vistos apenas como seres individuais, não se levando em conta o contexto institucional (ZEICHNER; LISTON, 1996). Duarte (2003), por sua vez, apontou o fato de as ideias de Schön serem pautadas em uma epistemologia que não valoriza o

\footnotetext{
2 As propostas de Schön podem ser analisadas nas suas obras: Argyris, C.; Schön, D. (1974) Schön, D. (1983). Schön, D. (1987).
} 
conhecimento específico. ${ }^{3}$ Portanto, faz-se necessário que analisemos também estudos que tratem dessa questão, com o objetivo de ampliar as ideias de Schön.

Influenciado pela discussão sobre a reflexão, Zeichner, ${ }^{4}$ que há décadas aderiu a esse Movimento em sua essência, admite que sua própria ideia sobre professor como prático reflexivo desenvolveu-se muito desde a década de 1980. O autor avalia positivamente a associação desse Movimento de Reflexão na Educação a um esforço para elevar o status do papel do profissional docente. Entretanto, chama a atenção para o fato de que há tendências de se utilizar o slogan da prática reflexiva para manter, de forma sutil, uma posição subserviente dos professores:

[...] sob a bandeira de emancipação dos professores [...]. Muitas das investigações feitas no campo da educação permanecem como uma atividade conduzida pelos que estão fora da sala de aula. Quando levados em conta, os professores são vistos como simples consumidores dessas investigações (ZEICHNER, 1993, p. 17).

Essa ideia é retomada em 1996, quando o autor observa que:

\begin{abstract}
O significado [da investigação em educação e/ou processo de formação] nem sempre está claro e, em alguns casos, a pretensão de um compromisso com a ideia de reflexão e liderança do professor não passa de um modo mais sutil e manipulativo de exercer controle sobre os professores e mantê-los em posição subalterna (ZEICHNER; LISTON, 1996, p. 77).
\end{abstract}

Zeichner (1993) afirma que se incorporaram ao discurso sobre prática reflexiva todas as crenças da comunidade educacional no que diz respeito a ensino, aprendizagem, escolaridade e ordem social, e que isso pode acarretar a virtual perda do significado do termo. Sustenta ainda que, mesmo considerando positivamente o fato de que os professores devem desempenhar um papel ativo na formulação de seu trabalho, é necessário que também se reconheça que a produção de conhecimentos acerca de um ensino de qualidade não é propriedade exclusiva das universidades e centros de investigação e desenvolvimento. Para o autor, os professores têm teorias importantes no estabelecimento de uma base codificada de conhecimento de ensino (ZEICHNER, 1993, p. 16).

Outra contribuição não menos importante destes estudos concerne à visão social da prática docente. Segundo o autor, o contexto social passa a ser visto como objeto de reflexão e análise e fonte de reflexão e formação. Zeichner (1998) observa, considerando a pesquisa de Adler (1993), que é recente a aceitação de estudos que os formadores de professores fazem sobre suas próprias práticas como parte da pesquisa sobre formação de professores. Para o autor, há nesse tipo de abordagem uma estreita conexão entre pesquisa e prática - são os

\footnotetext{
${ }^{3}$ Ver: Duarte, 2003.

${ }^{4}$ Kenneth M. Zeichner é professor e pesquisador, pertence a um grupo de pesquisa que estuda e trabalha com formação de professores nos EUA e países do Terceiro Mundo.
} 
estudos que os formadores de professores realizam sobre sua própria prática (pesquisa ação) -, pois acabam incorporando mudanças em suas ações como parte do próprio processo de pesquisa, descrevendo, inclusive, como essa prática influenciou o seu próprio trabalho. $\mathrm{O}$ autor diz que as interações:

[...] com licenciados e com professores que fazem pesquisa-ação sobre suas próprias práticas fizeram com que eu adquirisse uma perspectiva muito mais ampla sobre o processo pesquisa-ação, e que somente depois que comecei a levar em consideração maneiras de fazer pesquisa-ação que diferiam das utilizadas na pesquisa acadêmica convencional é que comecei a ver os professores se entusiasmarem com as próprias investigações sobre o seu trabalho e ver algumas transformações no pensamento e na prática (ZEICHNER, 1998, p. 84).

No que concerne à relação entre a reflexão e os processos de ensino e aprendizagem da Matemática, especificamente, nos apoiamos em estudos de Serrazina (1998, 1999). Em 1998, a autora apresentou resultados de um estudo empírico realizado em uma escola em Lisboa, por três anos, com professoras que lecionavam para os Anos Iniciais. Serrazina (1998) investigou as concepções sobre a Matemática e o seu ensino, as implicações destas nas práticas docentes e o modo como elas influenciaram as interpretações do movimento de renovação curricular de professoras que lecionavam Matemática.

Nesse sentido, a autora, ao pesquisar a capacidade de reflexão dos professores de Matemática com quem trabalhou, observou que há uma relação entre a autoconfiança e os conhecimentos específicos da área. Segundo observações da pesquisadora, a capacidade de refletir a própria prática:

[...] ocorre quando os professores ganham autoconfiança e são capazes de reflectir nas suas práticas. Isto pressupõe um elevado grau de conscientização que os ajude a reconhecer as suas falhas e fraquezas e a assumir um forte desejo de as ultrapassar (SERRAZINA, 1999, p. 163).

Desse modo, consideramos, assim como a autora, que o fato de priorizarmos a pesquisa que propicie ao professor um espaço para a discussão mais aprofundada do conteúdo poderia permitir uma maior profundidade também nas reflexões efetuadas durante e depois da pesquisa. Assim, apoiados nas ideias de Serrazina, escolhemos estudar o significado da representação fracionária dos números racionais a partir de uma pesquisa de intervenção com o objetivo de garantir um maior aprofundamento das reflexões. Baseamo-nos também em pesquisas da autora, entre outras, para focar nosso trabalho em um campo específico do conhecimento - a Matemática -, e em um conteúdo determinado - a representação fracionária dos números racionais.

Ainda sobre a questão da reflexão específica no ensino de Matemática, Serrazina em parceria com Oliveira afirma que: 
[...] quando se pensa em ensino da Matemática, a reflexão pode partir de diversos aspectos, uns relativos à organização e gestão da sala de aula, outros relativos à compreensão da matemática, isto é, à medida que se "conversa reflexivamente com a situação" vai-se sendo capaz de tornar explícito o seu conhecimento matemático falar sobre os procedimentos e não apenas descrevê-los (OLIVEIRA; SERRAZINA, 2002, p. 5).

A análise desses aspectos parece-nos fundamental neste trabalho, visto que tratamos do desenvolvimento profissional docente e fizemos das entrevistas não só uma descrição de procedimentos, mas um momento de reflexão sobre esses e outros aspectos, para tentar explicitar não só o conhecimento matemático, ou até mesmo didático, sobre determinado assunto, mas principalmente suas relações com a docência.

Outra questão não menos importante a ser levada em conta é a do tempo necessário para que esse processo realmente se efetive. Mais uma vez observamos nos estudos de Oliveira e Serrazina (2002), que, baseadas nas ideias de teorias em ação (Schön, 1983), chamam a atenção para o fato de ser necessário destinar um tempo para que os professores explicitem e avaliem essas teorias, ou seja:

Para isso têm de começar por explicitar as suas teorias defendidas (o que dizem sobre o ensino) e as suas teorias em uso (como se comportam na sala de aula). Só avaliando as compatibilidades e incompatibilidades que existem entre estes dois elementos da sua teoria de acção e os contextos nas quais ocorrem serão os professores capazes de aumentar o seu conhecimento do ensino, dos contextos e de si próprios como professores. Pode dizer-se que a reflexão contribui para a consciencialização dos professores das suas teorias subjectivas, isto é, das teorias pessoais que informam a sua acção (OLIVEIRA; SERRAZINA, 2002, p. 8).

Isto posto, procuramos durante o processo de formação estabelecer certa rotina no que se refere à prática reflexiva. Buscamos também considerar, assim como as autoras, favorecer a reflexão em uma equipe com características colaborativas. Para as autoras, a reflexão "[...] funciona como o espaço onde se colocam e discutem as questões que resultam da prática, onde se sentem novas necessidades e se constroem novos conhecimentos" (OLIVEIRA; SERRAZINA, 2002, p. 6 - grifos nossos).

À luz dessas ideias, podemos afirmar que a formação de uma equipe colaborativa poderia se tornar um fator essencial para que a reflexão sobre a prática realmente ocorra. Tal característica a nosso ver poderia favorecer a aquisição de mais segurança e cumplicidade entre professores.

Em face das considerações feitas até aqui e da necessidade de uma real transformação em sala de aula, evidencia-se a importância de uma prática reflexiva. Nesse sentido, compreender todas as questões que perpassam essa prática parece ser fundamental, sejam elas apoiadas em estudos de Schön, cuja valorização da pesquisa na ação constituiu-se em base para o que se convencionou chamar de professor pesquisador, seja em contribuições de 
Zeichner, quando chama a atenção para a relevância da consideração do contexto social como objeto de reflexão e análise, seja nos estudos de Serrazina, que consideram essencial a reflexão a partir do trabalho colaborativo, envolvendo equipes de professores que lecionam Matemática para os Anos Iniciais.

Quanto ao objeto matemático: frações, é importante ressaltar que os significados indicados em nosso estudo foram apoiados na classificação proposta por Nunes, Campos, Magina e Bryant (2005), que, com base nas ideias de Vergnaud (1990), propõem que sejam considerados os invariantes: ordem e equivalência e quatro situações que pretendem dar significados à fração e às representações possíveis. Os significados de fração considerados por Nunes et al. (2005) são: relação parte-todo; quantidade intensiva; operador multiplicativo e quociente.

A relação parte-todo é definida por Nunes e Bryant (2009) apoiada em Behr, Harel, Post e Lesh $(1992 ; 1993)$ como uma quantidade dividida em um certo número de partes (y), do qual é retirado um número especificado (x). Os autores afirmam ainda que "o símbolo $\frac{x}{y}$ representa esta quantidade em termos de relação parte-todo" (NUNES; BRYANT, 2009, p.10). Já a fração como quociente é definida nesse mesmo estudo como a indicação de uma divisão e seu resultado. Os autores consideram fração como quociente quando duas grandezas, x e y são tratadas como componentes de uma divisão, ou seja, x como o dividendo e y como divisor, e pela operação divisão obtém-se uma única quantidade $\frac{x}{y}$.

Vale ressaltar que apenas esses dois significados aqui descritos foram objetos de estudo durante as sessões de formação por havermos constatado que a metodologia adotada durante nossas sessões não permitiria abranger todos os significados, em virtude da extensão do trabalho e das reflexões ocorridas. A escolha da relação parte-todo e quociente também se justificaram pelo fato de que documentos oficiais como os Parâmetros Curriculares Nacionais (PCN) indicarem a necessidade de que o professor trabalhe com esses dois significados já a partir dos primeiros anos do Ensino Fundamental quando tratar da temática números racionais (BRASIL, 1997, p.54).

Mais especificamente, optamos por trabalhar com a relação parte-todo uma vez que as orientações contidas nos PCN (1997), da mesma forma que uma diversidade de pesquisas, indicam a predominância da utilização por professores brasileiros da abordagem que recorrem a essa ideia (CAMPOS et al., 1995; NUNES; BRYANT, 1997; CANOVA, 2006; entre outros). Todavia, esses estudos apontam ainda que a apresentação das frações por parte do 
professor utilizando-se somente deste significado pode não ser adequada, sobretudo se o foco do ensino for procedimental. Por exemplo, já na década de 90, pesquisadores brasileiros afirmavam que:

\begin{abstract}
O modelo parte-todo (...) é tal que o professor apresenta sempre situações típicas, por exemplo, o inteiro sempre dividido em partes iguais em que o método de dupla contagem leva sempre a interpretações corretas. Dessa forma, a simples contagem de partes leva à linguagem correta para indicar a fração, sem que o aluno interprete, necessariamente, a fração como uma relação entre a parte e o inteiro enquanto unidade. (CAMPOS et al., 1995, p.4)
\end{abstract}

Ainda, segundo esses autores, tal processo pode dificultar a compreensão da ideia de equivalências, pois tal foco ignora "outras relações como a conservação de área, a manutenção da unidade, as diferentes representações" (ibid. p.4). Nesse sentido, consideramos ser importante investigar questões relativas aos processos de ensino e aprendizagem das frações envolvendo a relação parte-todo, levando em conta a reflexão sobre a prática e resultados de pesquisa na área de forma a ampliar os conhecimentos já construídos pelos professores envolvidos.

No tocante ao significado quociente, buscamos também nos documentos oficiais elementos que mostrem a relevância de nossa escolha. Os elaboradores do PCN (1997) ao sugerirem os conteúdos de Matemática para os Anos Iniciais do Ensino Fundamental (2º ciclo), propõem que aqueles abordados no ciclo anterior, como número natural, adição, medida etc, sejam ampliados, pelo estabelecimento de relações e pelo aperfeiçoamento dos procedimentos já vistos, com a finalidade de construir novos conhecimentos. Dessa forma, situações que envolvam o significado de quociente podem favorecer esse aprimoramento (p. $54)$.

Aliado a isso, observamos também outros estudos que mostram que o significado parte-todo não é suficiente para a ampliação do conjunto numérico dos naturais e sugerem que uma abordagem envolvendo outro significado poderá fazê-lo. Kieren (1988), por exemplo, discute que o trabalho com o modelo parte-todo induz ao processo de dupla contagem, não propiciando a introdução da criança no campo dos quocientes. Ou seja, consideramos que, para compreender que o conjunto dos racionais é uma extensão do conjunto dos números naturais, o aluno precisaria vivenciar situações em que a ideia da divisão fosse ampliada.

Além disso, apoiamo-nos também em Nunes et al. (2005), que inspirada em Streefland (1984) indicou que pode ser mais natural para a criança a introdução do conceito de fração por essa situação uma vez que pode ser desenvolvida por meio da partilha equitativa, muito presente na experiência diária do estudante. Entretanto é preciso ressaltar a necessidade de 
que o professor se aproprie destas ideias. Assim, o foco da nossa intervenção foi discutir e analisar com os docentes as possibilidades de introdução do conceito por meio de tais situações.

Nesse sentido, iniciamos nossa intervenção conforme descrito a seguir, levando em consideração os estudos aqui apresentados.

\section{Metodologia}

A pesquisa aqui descrita é de natureza qualitativa, no sentido definido por Bogdan e Biklen (1999). Para tanto, escolhemos investigar diferentes aspectos relacionados à reflexão de um grupo de professores, tomando como base suas observações sobre os processos de ensino e aprendizagem de frações durante e após um processo formativo.

Foram sujeitos desse estudo 17 professores experientes que lecionavam para os Anos Iniciais, uma vez que 14 lecionavam há mais de 10 anos e a metade com mais de 15 anos de magistério. Quanto à formação, todos eles possuíam o curso de magistério (no nível médio) e destes, 10 haviam cursado o ensino superior.

Para coleta de dados foram realizadas 16 sessões de 4 horas cada, das quais: três foram destinadas à aplicação do instrumento diagnóstico; nove sessões foram dedicadas aos estudos dos significados da representação fracionária dos números racionais e à vivência de metodologias diversificadas, objetivando o trabalho com frações; uma das sessões foi reservada para que os professores elaborassem uma sequência de trabalho desenvolvida com seus alunos em sala de aula; duas sessões foram voltadas às entrevistas. Estas entrevistas versaram sobre a formação inicial e sobre os tipos de abordagem utilizados anteriormente, pelos professores, para desenvolver o conceito de número racional em sua representação fracionária. Finalmente, realizou-se uma última sessão de entrevista um ano após a intervenção com a finalidade de verificar as reflexões feitas pelo professor depois da pesquisa.

Dessa forma, inicialmente foi apresentado aos professores e aos seus alunos um questionário contendo situações-problema envolvendo a ideia de fração. Esse instrumento serviu como diagnóstico e teve o objetivo de analisar e compreender as estratégias utilizadas pelos docentes e por seus alunos para a solução dos problemas propostos. Esse mesmo questionário apresentado ao grupo de professores foi composto de uma segunda parte com a finalidade de verificar o perfil dos sujeitos envolvidos. Além disso, solicitamos que os professores avaliassem seu trabalho sobre frações durante os anos anteriores à nossa pesquisa. 
A análise contendo os resultados apresentados pelos professores e por seus alunos serviu como base para a elaboração do material que seria objeto de estudo durante nossa intervenção.

Durante os três primeiros encontros da intervenção, discutimos sobre os resultados encontrados no instrumento diagnóstico, como uma atividade preparatória para os estudos que faríamos sobre os significados dos números racionais em sua representação fracionária. Reiteramos que apenas dois dos significados adotados nesta pesquisa foram objetos de estudo durante esses encontros: significado parte-todo e quociente. A seleção desses dois significados, em nossa opinião, pode também ser justificada, como já afirmado anteriormente, pelo fato de estarem mais associados às fases iniciais da construção do conceito de número racional e, consequentemente, por serem mais apropriados à identificação de pontos críticos relacionados tanto ao ensino quanto à aprendizagem.

Essas sessões foram dedicadas à reflexão sobre situações de ensino que pudessem permitir aos alunos vivências de contextos que os levassem a avançar na construção do conceito de número racional, em sua representação fracionária, com diferentes significados. Procuramos, ainda, a pedido do grupo de professores, apresentar possibilidades de tratamento metodológico para o desenvolvimento dos significados selecionados.

Foram utilizadas duas sessões para a realização da primeira entrevista, que versou sobre a formação inicial e sobre os tipos de abordagem utilizados, anteriormente, pelos professores, para desenvolver o conceito de número racional, em sua representação fracionária. Além disso, os docentes fizeram uma descrição do trabalho desenvolvido em sala de aula depois de nossa intervenção. A última entrevista foi realizada com o objetivo de averiguar a influência deste projeto sobre a prática pedagógica dos docentes após o término de nossa intervenção. Dessa forma, nossa coleta de dados foi realizada em quatro etapas:

\begin{tabular}{|c|l|c|}
\hline Etapas & Descrição & Número de sessões \\
\hline $1 .^{a}$ & $\begin{array}{l}\text { Coleta de dados: instrumento diagnóstico } \\
\text { referente aos alunos e professores envolvidos na } \\
\text { pesquisa }\end{array}$ & 3 \\
\hline $2^{a}$ & Intervenção & 1 \\
\hline $3 .^{a}$ & $\begin{array}{l}\text { Elaboração coletiva de uma sequência de trabalho } \\
\text { com frações }\end{array}$ & 2 \\
\hline $4 .^{a}$ & $\begin{array}{l}\text { Descrição do trabalho desenvolvido em sala de } \\
\text { aula por meio de entrevistas com os professores } \\
\text { envolvidos }\end{array}$ & \\
\hline
\end{tabular}

Quadro 1 - Etapas da pesquisa

Fonte: Garcia Silva (2007)

Ressaltamos que, além disso, os docentes fizeram uma descrição do trabalho desenvolvido em sala de aula depois de nossa intervenção, o qual será o foco de discussão 
deste artigo. A leitura dos depoimentos coletados permitiu-nos identificar aquelas falas mais significativas, do ponto de vista dos pesquisadores. Dessa forma, após tal seleção, procedemos à análise, buscando identificar convergências e divergências entre os entrevistados, estabelecendo correlações com outros estudos. Todavia, consideramos que para compreender os depoimentos apresentados nesta análise é importante antes descrever de forma sucinta a sequência de trabalho elaborada pelo grupo de professores.

Durante a sessão de formação destinada à elaboração da sequência, os professores analisaram o livro didático da escola e observaram que o estudo de frações era iniciado pela identificação dos termos, como numerador e denominador, com maior destaque para situações que envolvem o significado parte-todo, relacionando grandezas contínuas. Dessa forma, perceberam a necessidade de complementar o trabalho utilizando-se de materiais manipuláveis como dobraduras, Tangram e do livro O Pirulito do Pato, de Nilson José de Machado (2003).

Os materiais manipuláveis ajudariam, de acordo com nossos sujeitos, sobretudo, na compreensão do significado parte-todo. Já o livro favoreceria a contextualização uma vez que o autor conta a história de dois patinhos que ganham um pirulito da mãe e têm que dividi-lo de forma diferente à medida que chegam seus amiguinhos. Tal escolha também foi justificada por permitir a associação do pedaço do pirulito ao denominador da fração e a compreensão da relação de ordem de frações unitárias. Além disso, ainda segundo os professores, poderia favorecer a apresentação da fração como significado quociente na medida em que o professor problematizasse a situação por meio da alteração da quantidade de pirulitos e/ou de patinhos.

\section{Nossa análise: o professor relata o seu trabalho em sala de aula}

Como mencionamos anteriormente, este artigo apresenta os resultados da análise dos depoimentos de professores depois do processo formativo.

$\mathrm{Na}$ entrevista, elaboramos uma questão com o objetivo de ouvir a descrição que os professores fariam de sua prática após a intervenção. Acreditamos ser possível detectar as teorias defendidas, termo que Schön (1983) utiliza quando se refere ao discurso dos sujeitos pesquisados. Pretendíamos ainda observar nesses discursos o que esse autor chama de reflexão sobre a ação (reflection-on-action), ou seja, a reconstrução mental da ação para tentar analisá-la retrospectivamente.

Observamos, em todas as respostas, uma descrição de experiências consideradas 
positivas pelos professores. Um exemplo é o relato feito pelo Professor $3 \mathrm{~A}^{5}$ :

Foi muito gratificante e prazeroso porque, como já falei, as crianças puderam interagir mais, vendo coisas que aconteciam no dia a dia. Que elas já utilizavam fração e não sabiam que estavam lidando com fração quando estavam lidando com pizza. Então, eles puderam trazer para o cotidiano, a compreensão deles foi muito mais fácil. Quando eles construíram o livrinho didático deles, eles reconstruíram. A gente trabalhou o livro: 'O Pirulito do Pato', quando fizeram a parte do teatrinho e representaram tudo o que foi visto no livro. Depois eles desenharam então, eles participaram de uma forma muito gostosa. As crianças gostaram muito, participaram, entenderam o que é mais importante. Eles trabalharam com os discos de fração. Eles montaram e tiveram bastante noção do que é $\frac{1}{4}, \frac{1}{8}$ e que tudo aquilo lá fazia parte de um todo. Eu acho que a compreensão deles foi muito melhor e através de tudo isso os resultados foram mais significativos do que antigamente, porque você trabalhava de uma forma que você dava o conteúdo, cobrava ali através de atividades repetitivas e a criança nem sempre entendia, assimilava o que você estava dando. Ele estava fazendo mecanicamente. Agora não, eles entenderam realmente. Então eu achei que isso foi uma parte bem, vamos dizer, importante do trabalho porque a criança estava entendendo (PROFESSOR 3A, entrevista).

Analisando tanto o relato do Professor 3A como o depoimento dos demais professores,

observamos que a avaliação positiva esteve muito ligada ao encaminhamento metodológico do conteúdo:

[...] Nós começamos com o livro: lemos, fizemos a dramatização (o teatrinho). Eles adoraram. A partir dali eles já começaram a entender fração. Fizemos na sala com os papéis, depois que já haviam entendido o que é a representação em partes iguais [...] e daí para parte teórica foi muito mais fácil. As perguntas que surgiram, o entendimento deles, foi tão bom que eu nunca havia trabalhado assim: de surgir perguntas, sabe? De haver interesse. Por que $\frac{2}{8}$ pode ser $\frac{4}{16}$ ? (PROFESSOR 3B, entrevista).

Então, primeiro a leitura do livro de literatura. Trabalhamos com dramatização [...]. Então, quando chegou o final, todos já haviam entendido porque todos participaram da dramatização. Trabalhamos também com o papel parte-todo: eles cortaram, fizeram também o pirulito (PROFESSOR 3C, entrevista).

Ah! Foi ótimo aquele trabalho lá com o livro de literatura infantil. Não é o único paradidático, é? [...] Eu adorei o Tangram. [...] Aí eu olhei para ele (o aluno) e ele disse. Eu consegui fazer, professora. Num outro que não tem risco, ele disse, consegui fazer esse também. [...] Mas eu gostei, muito de trabalhar com o livro 'O Pirulito do Pato' com o Tangram. Foi muito bom mesmo (PROFESSOR 4D, entrevista).

Tais depoimentos parecem valorizar a participação ativa do aluno. A nosso ver, os

\footnotetext{
${ }^{5}$ Para apresentar estes dados, baseamo-nos nas respostas obtidas de cada professor, nomeados por turma $3\left(.^{\mathrm{a}}\right.$ série e $4 .^{\mathrm{a}}$ série) acompanhados de letras de $\mathrm{A}$ a $\mathrm{H}$. Assim, o professor $3 \mathrm{~A}$ era um dos que lecionavam para a terceira série.
} 
professores valorizaram a indicação de materiais manipuláveis e a utilização da literatura como um contexto, uma vez que vivenciaram um maior envolvimento dos estudantes. Quanto à utilização da literatura infantil, há indícios de que os professores encontraram, nessa alternativa o que Machado (1991) chama de essencialidade da impregnação. Segundo o autor:

Entre a Matemática e a Língua Materna existe uma relação de impregnação mútua. Ao considerarem-se estes dois temas enquanto componentes curriculares, tal impregnação se revela através de um paralelismo nas funções que desempenham uma complementaridade nas metas que perseguem uma imbricação nas questões básicas relativas ao ensino de ambas. É necessário reconhecer a essencialidade dessa impregnação e tê-la como fundamento para a proposição de ações que visem à superação das dificuldades com o ensino de Matemática (MACHADO, 1991, p. 10).

Verificando os relatos dos professores, observamos ainda que pela sequência organizada pelo grupo, na última sessão, seriam propostas aos alunos situações-problema envolvendo também quociente. Entretanto, durante a entrevista, notamos que os professores não enfatizaram a análise das situações selecionadas e as discussões ocorridas na sala, tendo havido uma preocupação maior no sentido de destacar a metodologia e os materiais utilizados. Somente quando questionamos sobre os significados trabalhados, esses significados foram mencionados. Para exemplificar, expomos um extrato da entrevista:

Professor 4B: Nós introduzimos a fração na quarta série [quinto ano] com 'O Pirulito do Pato', que é literatura infantil, né? Fizemos todo um trabalho de leitura e também fizemos um trabalho de interpretação de texto. Usamos o mosaico, que também foi discutido no curso, e eu fiz um trabalho com dobradura. Fizemos um painel e depois a gente inseriu o Livro Didático que é uma maneira mais teórica: primeiro a gente fez um trabalho de sensibilização com os alunos.

Entrevistadora: E quanto aos significados da fração, o que vocês trabalharam?

Professor 4B: Parte-todo e quociente que a gente trabalhou mais! (PROFESSOR 4B, entrevista)

Os depoimentos denunciam: manteve-se uma ênfase maior no trabalho com o significado parte-todo, porém notamos que nossa intervenção proporcionou aos docentes maior segurança para desenvolver o trabalho em sala de aula, refletindo na compreensão do aluno, assim como foi relatado por Serrazina (1999). Observamos ainda que esse processo permitiu a ampliação de algumas reflexões sobre a relação entre o ensino e a aprendizagem.

Por exemplo, durante o processo formativo, quando foi analisada a questão ilustrada no quadro 2, que tinha por objetivo verificar se os sujeitos identificariam o todo e as partes, além de utilizar a dupla contagem para representar a fração em uma situação estática. Nesse caso, o sujeito deveria levar em conta a conservação da área, isto é, a equivalência entre as 
partes em que o todo foi dividido.

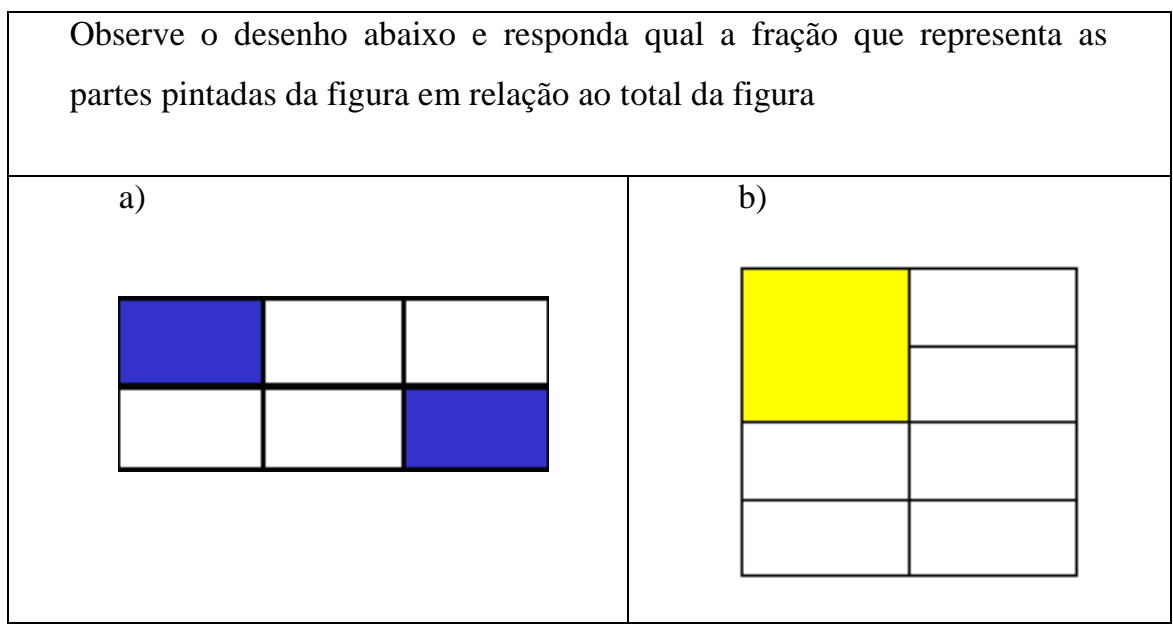

Quadro 2 - Questão do questionário

Fonte: Garcia Silva (2007, p.119)

$\mathrm{Na}$ análise inicial, o grupo de professores classificou essa questão como fácil e a consideraram como muito trabalhada de maneira regular em sala de aula. Entretanto, quando comentamos que os índices de acerto dos alunos foram inferiores a 50\%, e que, especialmente o item b, apresentou uma taxa de 7,5\% de acertos, os professores se espantaram e, após uma intensa discussão sobre esse tipo de erro, os profissionais teceram comentários como:

Foi bom acontecer isso para que percebêssemos que não basta dizer que é só colocar embaixo o número de partes em que o todo foi dividido e em cima quantas partes foram pintadas (PROFESSOR 3F, entrevista).

É essa questão veio para dar um chacoalhão na gente. Se for isso o que mais fazemos na sala de aula e não tem bom resultado, sinal que precisamos procurar outras formas de passar isso para os alunos (PROFESSOR 4E, entrevista).

Tivemos a sensação de que essa análise trouxe muito desconforto, revelado pelas observações dos próprios professores, o que nos remete aos estudos de Serrazina (1999), quando discute a relação entre o processo de reflexão dos professores portugueses e a autoconfiança que possibilitou "um elevado grau de consciencialização" que os ajudou a "reconhecer as suas falhas e fraquezas e a assumir um forte desejo de ultrapassá-las" (SERRAZINA, 1999, p. 163). Observamos ainda indícios de que pudesse ter havido mudança de atitude em relação à prática destes profissionais, visto que durante o planejamento das aulas que discutiriam os temas os professores, espontaneamente, demonstraram preocupar-se com a preparação de situações que considerassem a conservação da área.

Analisando este depoimento, observamos que essa reflexão pode ter relação com o conhecimento adquirido durante a intervenção, pois estudos como os de Blanco e Contreras 
(2002) afirmam que, quando professores têm pouco conhecimento dos conteúdos, eles se apoiam na memorização. Outros depoimentos mostram que esse processo permitiu reflexões sobre a relação entre o ensino e a aprendizagem, levando em conta o interesse e os questionamentos feitos pelos alunos:

[...] As perguntas que surgiram, o entendimento deles, foi tão bom que eu nunca havia trabalhado assim: de surgir perguntas, sabe? De haver interesse. Por que 2/8 pode ser 4/16? [...] É a equivalência. Eu nunca tinha dado, nesses anos todos, eu cheguei a trabalhar equivalência. Porque você vai, né? No livro didático: Fração porque é fração, numerador, denominador e fica naquilo, eles não têm noção, não dá tempo. E com o novo, com o inovador, com as perguntas e o interesse da sala... Eu até chamei uma colega para ver (PROFESSOR 3B, entrevista).

Observamos aqui que o professor apresenta uma mudança relacionada à prática bastante importante, uma vez que a equivalência é uma das ideias principais quando lidamos com frações. Estudos como os de Machado e Meneses (2006), por exemplo, apontam que os alunos por eles pesquisados sabiam reconhecer as frações representadas pelas partes pintadas, mas não identificavam as equivalentes. Um dos professores declarou que esse trabalho permitiu-lhe analisar descobertas relacionadas ao processo de aprendizagem dos alunos:

[...] Os alunos que ainda tinham dificuldades para entender o que era aquela hora do todo, a parte... Eles ficavam assim, sempre um perto do outro para estar trocando ideias mesmo àquela coisa que a gente tem que parar para pensar um pouco na prática da gente, não é? Eu consegui rever muita coisa da minha prática porque às vezes a gente olha assim uma sala e imagina que todo mundo está aprendendo tudo ao mesmo tempo do jeitinho que você está ensinando. Aí, você percebe que para refletir que cada um tem uma cabecinha, um pensa de uma forma. Então, tinha hora das perguntas que eu fazia e cada grupo respondia de uma forma e chegavam ao mesmo resultado. Então, isso é importante refletir: Matemática, é isso, existem várias formas de pensar e alcançar um resultado, e eu não tinha parado para pensar nisso até então. (...) até que eu achava que estava ensinando, não é? Aí a gente acaba repensando essa prática e vendo que na verdade a gente está aprendendo junto, está construindo o conceito com eles, não é? (PROFESSOR 4G, entrevista).

O professor, ao longo da entrevista, relata a reflexão feita durante a ação, ou seja, depois de propor atividades problematizadoras, percebeu que os alunos utilizam estratégias diferentes para resolver o problema. É importante salientar que essa é uma questão muito discutida durante nossa intervenção. Entretanto, acreditamos que, no caso deste professor, houve a real compreensão do processo de aprendizagem do aluno somente na observação durante a ação. Nesse sentido, observamos aqui o princípio descrito por Zeichner (1993) e reafirmado por Serrazina (1998, 1999), o qual considera que, à medida que o professor reflete sobre a sua prática, vão ocorrendo análises, críticas, reestruturação e incorporação nova de conhecimentos que poderão respaldar o significado das ações posteriores. 
Observamos que, em geral, os professores avaliaram positivamente os resultados, dizendo haver alcançado os objetivos. Dentre eles, alguns atribuíram à metodologia utilizada o fato de haver despertado um maior interesse no aluno, como no exemplo do Professor 4B, que se expressou dizendo: "Senti mais alegria nas crianças. Prazer em aprender. Fração não é uma coisa mecânica, que você só passa e eles executam” (PROFESSOR 4B, entrevista).

Houve também professores que analisaram seus resultados comparando-os com aqueles obtidos na prova do Sistema de Avaliação de Rendimento Escolar do Estado de São Paulo - SARESP (SÃO PAULO, 2005), e avaliaram que haviam atingido, parcialmente, seus objetivos: "Eu acho que alcancei uma boa parte. Eu fiquei feliz com meus alunos na aplicação do Saresp. Nós ficamos ansiosos... a gente sabia que Matemática iria mexer, deu pra entender?" (PROFESSOR 4F).

Nestes depoimentos ainda percebemos indícios de que, a partir das reflexões durante o processo, poderão ocorrer ações formativas posteriores, significando uma busca por parte dos sujeitos envolvidos por conhecimento e troca de informações, conforme pode ser observado nos textos a seguir:

E com o novo, com o inovador, com as perguntas e o interesse da sala... Eu até chamei uma colega para ver.

- Rosana, vem ver o interesse.

Em seguida a Luisa chamou, por isso que eu disse que houve interação entre a gente porque a Luisa falou:

- Ana Júlia, eles estão perguntando coisas de fração - aí a gente vai repartir, vai mostrar, aí a gente fez a pizza na lousa [...] (PROFESSOR 3B, entrevista).

[...] Eles viram o livro 'O pirulito do pato'. Eu já havia trabalhado essa folha. Ai', eles diziam: Nossa, é mesmo... acontece isso mesmo, dá isso mesmo. Eu saí para conversar com as meninas sobre o livro, pois eu estava ainda com algumas dúvidas. Aí saí de sala em sala perguntando para todo mundo o que já havia trabalhado. Nós trocamos bastante experiência com relação a isso... (PROFESSOR 4D, entrevista).

Nesse ano trabalhei com frações que estava no conteúdo de $4 .^{a}$ série $\left[5 .^{\circ}\right.$ ano], e também é a primeira vez que trabalho nessa série [ano]. Com a ajuda dos colegas montamos uma sequência didática e iniciei o trabalho com a utilização do livro ' $O$ pirulito do pato', depois, algumas atividades do livro didático de Oscar Guelli (PROFESSOR 4E, entrevista).

Como pudemos observar nos depoimentos aqui apresentados, a colaboração e a reflexão sobre o processo de ensino e aprendizagem da representação fracionária dos números racionais desempenhou também um papel importante nesta pesquisa. 
Notamos um cultivo da reflexão como uma prática social, por meio da qual, segundo Zeichner (1993), "grupos de professores podem apoiar e sustentar o crescimento uns dos outros” (ZEICHNER, 1993, p. 23). Sobre esse tema, o autor complementa:

\begin{abstract}
A definição de desenvolvimento do professor, como uma atividade que deve ser levada a cabo individualmente, limita muito as possibilidades de crescimento do professor. Uma das consequências deste isolamento dos professores e da pouca atenção dada ao contexto social do ensino no desenvolvimento dos professores é que estes acabam por ver os seus problemas como só seus, sem terem qualquer relação com os dos outros professores ou com a estrutura das escolas e os sistemas educativos (ZEICHNER, 1993, p. 23).
\end{abstract}

Foi possível perceber ainda durante o desenvolvimento deste estudo o crescimento da disposição manifestada pelos professores de estudar de forma coletiva - o que pode ter uma relação com a troca de experiências observadas durante o processo formativo. Parece-nos haver indícios de que os sujeitos envolvidos demonstraram reconhecer que "o processo de aprender a ensinar se prolonga durante toda a carreira do professor" (ZEICHNER, 1993, p. 17), apontado pelo autor como mais uma característica da reflexão.

\title{
5 Considerações finais
}

Durante nossa intervenção observamos que a reflexão permitiu, além do avanço na compreensão do objeto matemático, o aprimoramento da análise de questões relacionadas ao ensino e aprendizagem que não haviam sido discutidas até então.

Consideramos que os depoimentos dos professores durante a realização das entrevistas nos indicaram que a reflexão durante a intervenção favoreceu algumas mudanças importantes quanto à prática pedagógica, em especial, as relacionadas aos recursos metodológicos. Observamos que os professores enfatizaram a utilização da literatura infantil e materiais manipuláveis, como meios possíveis de contextualizar uma situação. Acreditamos que algumas descobertas não seriam possíveis se a formação não tivesse ocorrido na própria escola com a participação de todos os professores e se não houvesse, no grupo, o espírito colaborativo. Foi na interação, na troca de experiências, na dúvida tirada na porta da sala, no corredor ou mesmo no cafezinho que se garantiu que todos experimentassem imprimir uma nova abordagem ao tema. Isso oportunizou um entendimento maior de questões relacionadas ao ensino e aprendizagem da representação fracionária dos números racionais.

Todavia, temos que considerar ainda outras questões de ordem didática, como a importância de levar em conta as dificuldades apresentadas pelos alunos, como as relativas à conservação da área, por exemplo, ou mesmo sobre a necessidade de trabalhar com os 
diferentes significados das frações e com grandezas contínuas e discretas, também muito debatidas durante os encontros, mas que não ficaram em evidência ao longo da entrevista. Apesar de terem sido levadas em conta pelos professores na preparação da sequência de trabalho, não foram citadas, espontaneamente, na entrevista.

Nesse sentido, é necessário acrescentar que a formação oferecida para a coleta de dados deste estudo não incluiu, por exemplo, algumas sessões destinadas à observação e discussão do trabalho desenvolvido pelo professor em sua sala de aula depois da preparação da sequência. Acreditamos que isso permitiria ao grupo ampliação das discussões ocorridas durante o processo formativo. Poderíamos com isso, retomar e clarificar as discussões sobre as dificuldades apresentadas pelos estudantes, a necessidade de trabalhar com os diferentes significados e, sobretudo, acerca da introdução da fração por meio do significado quociente. Diante do exposto consideramos que o processo vivido reforça a nossa convicção que, para que a formação seja entendida como processo contínuo e permanente de desenvolvimento profissional, é necessário que o professor tenha disponibilidade de tempo e de espaço, os quais possibilitem o estudo e a pesquisa in loco, proporcionando-lhe reais condições para continuar aprendendo de forma colaborativa.

A nosso ver, para que a formação seja entendida como processo contínuo e permanente de desenvolvimento profissional, é necessário que o professor tenha disponibilidade de tempo e de espaço, os quais possibilitem o estudo e a pesquisa in loco, proporcionando-lhe reais condições para continuar aprendendo de forma colaborativa. Concordamos com Tardif, Lessard e Lahaye (1991) quando se referem à maneira como o saber relacionado à prática ou à experiência vai se organizando e estruturando, permitindo que o professor produza algumas ideias pessoais, "das quais a mais importante consiste na confirmação, pelo docente, de sua própria capacidade de ensinar e de sua performance na prática da profissão" (TARDIF et al., 1991, p. 229). Essas certezas relativas ao contexto de seu trabalho só podem ser alcançadas se o professor tiver espaço para estudar, analisar e refletir sua prática.

\section{Referências}

ADLER, S. Teacher education: research as reflective practice. Teaching and Teacher Educations, Great Britam. v. 9, n. 2, p. 159-167, 1993.

ARGYRIS, C.; SCHÖN, D. Theory in practice: increasing professional effectiveness. San Francisco: JosseyBass. 1974 
BEHR, M., HAREL, G., POST, T., \& LESH, R. Rational number, ratio, proportion. In: D. A. Grouws (Ed.). Handbook of Research on Mathematics Teaching and Learning. New York: Macmillan, p. 296-333. 1992.

BEHR, M., HAREL, G., POST, T., \& LESH, R.. Rational Numbers: Toward a Semantic Analysis. In: T. Carpenter, E. Fennema e T. Romberg (Eds.), Rational Numbers - An Integration of Research. Hillsdale, New Jersey: LEA, p. 13-48. 1993.

BLANCO, L; CONTRERAS, L. Un modelo formativo de maestros de primaria, en el área de matemáticas, en el ámbito de la geometria. In:Contreras, L.C. y Blanco, L.J (Org). Aportaciones a la formación inicial de maestros en el áreas de matemáticas: una mirada a la práctica docente. Cáceres: Universidad de Extremadura, 2002. p. 92-124.

BOGDAN, R.; BIKLEN, S. Investigação qualitativa em educação: uma introdução à teoria e aos métodos. Porto: Porto Ed. 1999.

BRASIL. Ministério da Educação. Secretaria de Educação Básica. Secretaria de Educação Fundamental. Parâmetros Curriculares Nacionais para o Ensino Fundamental: Matemática. Brasília: MEC/SEB/SEF, 1997.

BRASIL. Referenciais para formação de professores. Brasília: MEC/SEB/SEF, 2002.

CAMPOS, T.; JAHN, A. P.; LEME DA SILVA, M. C.; SILVA, M. J. da. Lógica das equivalências. Relatório de pesquisa não publicado. São Paulo: PUC, 1995.

CANOVA, R.F. Crença, concepção e competência dos professores do $10^{\circ}$ e $2 .^{\circ}$ ciclos do ensino fundamental com relação à fração. 2006. 214 f. Dissertação (Mestrado em Educação Matemática) Pontifícia Universidade Católica, São Paulo. 2007. Disponível em: http://www.pucsp.br/pos/edmat/ma/dissertacao/raquel_factori_canova.pdf. Acesso em: 01 jul. 2012.

DUARTE, N. Conhecimento tácito e conhecimento escolar na formação do professor (por que Donald Schön não entendeu Luria). Educação \& Sociedade [on line], Campinas, v. 24, n. 83,pp. 601-625.). 2003. Disponível em: <http://www.scielo.br/scielo.php?pid=S0101$73302003000200015 \&$ script=sci_arttext $>$. Acesso em: 18 out. 2014.

GARCIA SILVA, A. F. O Desafio do Desenvolvimento Profissional Docente: análise da formação continuada de um grupo de professores das séries iniciais do Ensino Fundamental, tendo como objeto de discussão o processo de ensino e aprendizagem de frações. 2007. 308 f. Tese (Doutorado em Educação Matemática) - Pontifícia Universidade Católica, São Paulo, 2007. Disponível em: <http://www.pucsp.br/pos/edmat/do/tese/angelica_fontoura_garcia.>. Acesso em: 01 jul. 2012.

KIEREN, T. Personal knowledge of rational numbers: Its intuitive and formal development. In: J. Hiebert \& M. Behr (Eds.), Number concepts and operations in the middle-grades. Reston (VA): National Council of Teachers of Mathematics, 1988, p. 53-92.

MACHADO, C. T. O. MENEZES, J. E.. A construção do conceito de equivalência de frações numa abordagem significativa: uma contribuição da Teoria dos Campos Conceituais de Vergnaud. In: $1^{\circ}$ Seminário Internacional de Pesquisa em Educação Matemática. 2006, Pernambuco, Anais do 1 Seminário Internacional de Pesquisa em Educação Matemática. Recife: Centro de Educação da UFPE. 2006.V. Único. p. 01.09.

MACHADO, N. J. Matemática e língua materna: análise de uma impregnação mútua. 2. ed. São Paulo: Cortez, 1991.

MACHADO, N. J.O Pirulito do Pato. São Paulo: Scipione, 2003. 
NUNES, T.; BRYANT, P. Crianças fazendo matemática. Porto Alegre: ArtesMédicas, 1997.

NUNES, T.; BRYANT, P.; CAMPOS, T. M. M.; MAGINA, S.; BRYANT, P. Educação

matemática: números e operações numéricas. São Paulo: Cortez. 2005.

NUNES, T.; BRYANT, P. Key understandings in mathematics learning, Paper 3: Understanding rational numbers and intensive quantities. Nuffield Foundation. 2009. Disponível em <http://www.nuffieldfoundation.org/reports>. Acesso em 18 de outubro de 2014.

OLIVEIRA, I.; SERRAZINA, L. A reflexão e o professor como investigador. In: GTI (Ed.). Reflectir e investigar sobre a prática profissional. Lisboa: APM, 2002. p. 29-42.

SÃO PAULO (Estado). Secretaria da Educação. Sistema de avaliação do rendimento escolar do Estado de São Paulo - SARESP 2005: Prova 5. ${ }^{a}$ Série. São Paulo. Disponível em:

http://saresp.fde.sp.gov.br/2005/subpages/versoes_provas_series.htm. Acesso em: 8 abril. 2013.

SCHÖN, D. The reflective practitioner: How Professionals Think in Action. London: Temple Samith, 1983.

SCHÖN, D. Educating the reflective practitioner - toward a new design for teaching e learning in the professions. San Francisco: Jossey-Bass. 1987

SERRAZINA, L. Teacher's professional development in a period of radical change in primary mathematics education in Portugal. 1998. 406 páginas. Tese (PhD in Mathematics Education) Universidade de Londres. Lisboa: APM. 1998.

SERRAZINA, L. Reflexão, conhecimento e práticas lectivas em matemática num contexto de reforma curricular no 1. ${ }^{\circ}$ ciclo. Quadrante, Lisboa, V.8, n. 9, p. 139-167,1999.

STREEFLAND, L. Search for the roots of ratio: some thoughts on the long term learning process. (Towards ... A theory) Part 1: Reflections on a teaching experiment. Educational Studies in Mathematics, Dordrecht, v. 15, n. 4, p. 327-348, 1984

TARDIF, M.; LESSARD, C.; LAHAYE, L. Os professores face ao saber: esboço de uma problemática do saber docente. Teoria \& educação, Porto Alegre: Pannonica, v. único, n. 4, p. 215-233, 1991.

VERGNAUD, G. La théorie des champs conceptuels. Recherches en Didactique des Mathématiques, Grenoble, v. 10, n. 23, p. 133-170, 1990.

ZEICHNER, K. Formação reflexiva de professores: ideias e práticas. Lisboa: Educa, 1993.

ZEICHNER, K.; LISTON, D. Reflective teaching: an introduction. Mahwah, n.j.:Erbaum, 1996.

ZEICHNER, K. Tendências da pesquisa sobre formação de professores nos Estados Unidos. Trad. Lólio Lourenço de Oliveira. Revisão técnica Elsa Garrido. Trabalho apresentado na XX Reunião Anual da ANPED, Caxambu, set. 1997. Revista Brasileira de Educação, n. 9, 1998. Disponível em: http://anped.tempsite.ws/novo_portal/rbe/rbedigital/RBDE09/RBDE09_07_KENNETH_M_ZEICHN ER.pdf acesso em: 18 outubro 2014

Submetido em Junho de 2013. Aprovado em Fevereiro de 2014. 